\title{
Post-Transplantation Diabetes Mellitus
}

Syed Haris Ahmed (1) Kathryn Biddle $\cdot$ Titus Augustine

Shazli Azmi

Received: January 3, 2020 / Published online: February 24, 2020

(C) The Author(s) 2020

\section{ABSTRACT}

Solid organ transplantation (SOT) is an established therapeutic option for chronic disease resulting from end-stage organ dysfunction. Long-term use of immunosuppression is associated with posttransplantation diabetes mellitus (PTDM), placing patients at increased risk of infections, cardiovascular disease and mortality. The incidence rates for PTDM have varied from 10 to $40 \%$ between different studies. Diagnostic criteria have evolved over the years, as a greater understating of PTDM has been reached. There are differences in pathophysiology and clinical course of type 2 diabetes and PTDM. Hence, managing this condition can be a challenge for a diabetes physician, as there are several factors to consider when tailoring therapy for post-transplant patients to achieve better glycaemic as well as long-term transplant outcomes.

Enhanced Digital Features To view enhanced digital features for this article go to https://doi.org/10.6084/ m9.figshare.11830092.

S. H. Ahmed (四)

Countess of Chester Hospital NHS Foundation

Trust, Chester, UK

e-mail: asyedharis76@gmail.com

K. Biddle

St George's University Hospitals NHS Foundation

Trust, London, UK

T. Augustine $\cdot$ S. Azmi

Manchester University NHS Foundation Trust, Manchester, UK
This article is a detailed review of PTDM, examining the pathogenesis, diagnostic criteria and management in light of the current evidence. The therapeutic options are discussed in the context of their safety and potential drug-drug interactions with immunosuppressive agents.

Keywords: Calcineurin inhibitors; Diabetes mellitus; Graft failure; Macrovascular; Microvascular; Mortality; mTOR inhibitors; Post-transplantation; Rejection; Steroids

\section{Key Summary Points}

Post-transplantation diabetes mellitus (PTDM) is a known complication of solid organ transplantation.

PTDM is associated with infections, cardiovascular morbidity and mortality.

There is an overlap of risk factors for type 2 diabetes mellitus and PTDM; however, the pathophysiology and clinical course are different; hence, it is important to be aware of PTDM and understand how it is diagnosed and treated.

Treatment strategies should be tailored to the individual.

There are opportunities for prevention of PTDM by modifying risk factors. 


\section{INTRODUCTION}

Solid organ transplantation (SOT) is now an established and routine therapeutic option that has transformed the survival and quality of life of patients with end-organ dysfunction [1]. It however requires the long-term use of immunosuppression with inherent morbidity that may affect transplant outcomes. These include post-transplant diabetes mellitus (PTDM), hyperlipidaemia and hypertension, placing patients at increased risk of cardiovascular disease and mortality. PTDM is also associated with reduced kidney graft survival $[2,3]$ and infections [4, 5]. Emphasis has been placed on trying to identify those patients who are at risk of PTDM to improve their outcomes. Furthermore, improvements in immunosuppressive protocols have seen a decline in the rates of PTDM.

There have been changes in the nomenclature of PTDM over the past 50 years. More recently, it was known as new onset diabetes after transplantation (NODAT). However, it was thought that this terminology implied that diabetes mellitus was excluded prior to transplantation and only developed subsequently. As many centres did not screen patients prior to transplantation at the time, this nomenclature was misleading. Therefore following on from the International Consensus Meeting in 2013, the first recommendation was to change the terminology back to PTDM, as it was originally known [6]. This is a more inclusive term for diabetes that is diagnosed after transplantation without specific reference to any previous history of diabetes. The consensus provided a streamlined guidance for PTDM to align the diagnostic and therapeutic challenges faced in management of this condition.

This article aims to review the current literature on PTDM to provide guidance on the diagnosis, prevention and management. It is based on previously conducted studies and does not contain any studies with human participants or animals performed by any of the authors.

\section{DIAGNOSIS}

Historically, there has been a lack of clear guidance on the criteria to diagnose PTDM. The early definition was simply based on a need for insulin or oral therapy after transplantation leading to considerable under-diagnosis of the condition. Previous consensus reports in 2003 [7] and 2005 [8] recommended the use of the oral glucose tolerance test (OGTT) to be performed twice according to the World Health Organisation (WHO) criteria. In 2012 the American Diabetes Association and WHO added HbA1c as a test for the diagnosis of type 2 diabetes mellitus (type $2 \mathrm{DM}$ ) (Table 1) [9].

The differences in pathophysiology between type 2 diabetes and PTDM suggest the same criteria may not simply be applied to both conditions. This led to the International Consensus Meeting in 2013, which aimed to address these issues and provide a clearer directive. The consensus recommends delaying the screening and diagnosis of PTDM until at least 45 days after transplantation to allow for immunosuppression levels to be stabilized [6]. OGTT is the gold standard for diagnosis as this method is able to identify more patients with PTDM than fasting glucose alone $[10,11]$. The difference in pathophysiology between type 2 diabetes mellitus and PTDM means that the detection of PTDM is higher using OGTT $[12,13]$.

A further advantage of an OGTT is being able to diagnose impaired glucose tolerance (IGT), which is an independent risk factor for longterm development of PTDM, CVD and mortality both prior to transplantation and after

Table 1 Diagnostic criteria for diabetes mellitus

Criteria for diagnosis of diabetes mellitus

Symptoms of diabetes plus random plasma

glucose $>200 \mathrm{mg} / \mathrm{dl}(11.1 \mathrm{mmol} / \mathrm{l})$

Fasting plasma glucose $>126 \mathrm{mg} / \mathrm{dl}(7.0 \mathrm{mmol} / \mathrm{l})$

2-h plasma glucose $>200 \mathrm{mg} / \mathrm{dl}(11.1 \mathrm{mmol} / \mathrm{mol})$ during OGTT

$\mathrm{HbAlc}>6.5 \%(48 \mathrm{mmol} / \mathrm{mol})$ 
$[2,14,15]$. A recent review from Jenssen et al. recommended the use of an OGTT, 2 months post-SOT [16]. Furthermore, they recommend if resources are limited, the OGTT, which can be time consuming, may be reserved for patients with a $\mathrm{HbA} 1 \mathrm{C}>5.7 \%(39 \mathrm{mmol} / \mathrm{mol})$ as this method will detect $90 \%$ of all individuals with PTDM whilst administering an OGTT in only half of the patients who have had a transplant $[10,17]$.

The use of HbA1c to diagnose PTDM has also attracted controversy. In 2012, both the ADA and WHO advocated the use of HbA1c as the primary test to diagnose type 2 diabetes mellitus. However, in the 2014 consensus report it was decided that HbA1c should not be the sole criterion and must be used with caution in the post-transplantation phase. In particular, a HbA1c done within the first 12 months of transplantation may underestimate PTDM and needs further tests for corroboration [6]. The fallacies of using HbA1c early post-transplantation are due to the effects of post-transplant anaemia on red blood cell turnover as well as dynamic renal allograft function. Janssen et al. suggest that HbA1c could be an adequate diagnostic tool however in a stable phase such as 1 year after transplantation [16]. Although the 2014 consensus report has streamlined the diagnosis of PTDM there still needs to be further evidence to establish which tests to use at which time and perhaps a combination of $\mathrm{HbA1C}$, OGTT \pm fasting/random glucose could be used $\geq 45$ days after transplantation (Table 2).

There is no consensus as to when the end date for diagnosis of PTMD should be. However, it is thought that actual PTDM occurs within 6 months of transplantation as a result of the high doses of induction and maintenance immunosuppression during this period. It is interesting that 6 months after transplantation the annual incidence of diabetes is similar to those on the waiting list (approximately 6\%) [18]. Therefore, it is difficult to distinguish whether this diabetes is transplant-related or whether it is type $2 \mathrm{DM}$ that would have occurred despite transplantation. Furthermore, perhaps emphasis should be placed on excluding DM prior to transplantation as the disease process and outcomes in PTDM are different to
Table 2 Recommendations for screening and diagnosis of PTDM

\begin{tabular}{ll}
\hline $\begin{array}{l}\text { Time post- } \\
\text { transplant (days) }\end{array}$ & Diagnosis \\
\hline $0-45$ & Do not diagnose PTDM \\
$46-365$ & OGTT \\
& Fasting glucose $\geq 126 \mathrm{mg} / \mathrm{dl}$ \\
& $(\geq 7.0 \mathrm{mmol} / \mathrm{l})$ and $/ \mathrm{or}$ \\
& 2-h plasma glucose $\geq 200 \mathrm{mg} / \mathrm{dl}$ \\
& $(\geq 11.1 \mathrm{mmol} / \mathrm{l})$ \\
& Fasting glucose \\
& Fasting glucose $\geq 126 \mathrm{mg} / \mathrm{dl}$ \\
& $(\geq 7.0 \mathrm{mmol} / \mathrm{l})$ \\
& Random glucose $\geq 200 \mathrm{mg} / \mathrm{dl}$ \\
& $(\geq 11.1 \mathrm{mmol} / \mathrm{l})$ \\
& HbAlc $>6.5 \%(48 \mathrm{mmol} / \mathrm{mol}):$ use \\
& cautiously as will underestimate \\
& PTDM, if used $<1$ year post- \\
& transplant \\
& OGTT \\
& HbAlc \\
& Fasting/random glucose \\
\hline 365 &
\end{tabular}

type $2 \mathrm{DM}$. This may also guide the choice of immunosuppressive agents.

\section{INCIDENCE}

There is considerable variation in the reported incidence of PTDM reflecting the considerable heterogeneity in reports due to a historical lack of diagnostic criteria, length of follow-up, type of organ transplanted and immunosuppressive regimen. The reported rates of PTDM after kidney transplantation are 10-40\% [19] (Fig. 1). Vincenti et al. reported an incidence of $20.5 \%$ at 6 months after renal transplantation [17]. After heart transplantation, when OGTT has been used as the diagnostic criterion, the incidence has been reported at $20-28 \%$ at 5 years [20-22]. However, 5 years after liver transplantation the incidence of PTDM is reported at almost 40\% 


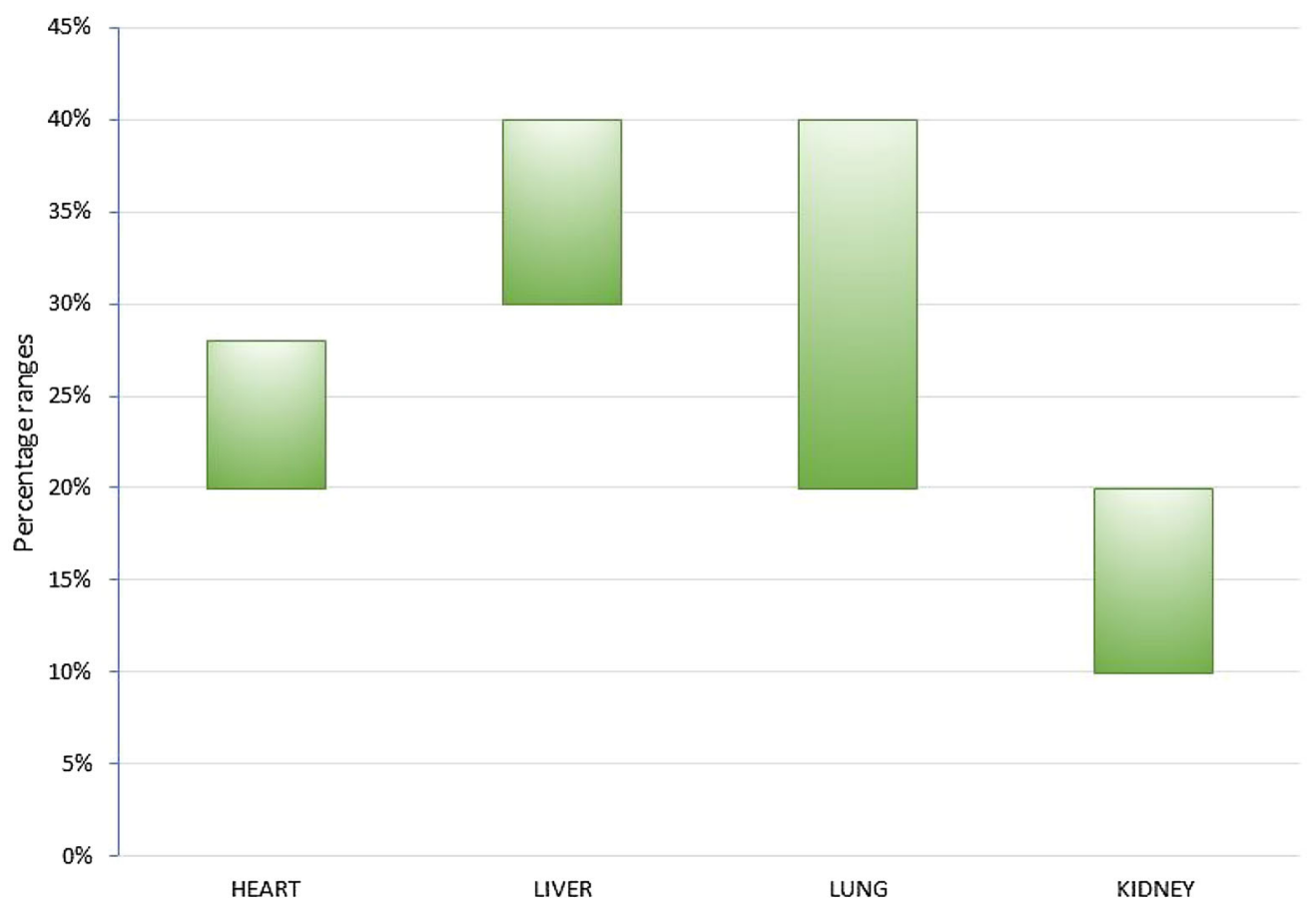

Fig. 1 Cumulative 5-year incidence of PTDM in heart, liver, lung and kidney transplant patients after the adoption of the OGTT as the gold standard for diagnosis

$[23,24]$. PTDM after lung transplantation has an accumulated incidence of $20-40 \%$ [16]. There has however been a decline in the incidence of PTDM, which may be related to the refinement of modern immunosuppression protocols and the embracement of revised diagnostic criteria. In studies using OGTT for diagnosis, the incidence of PTDM after kidney transplantation in 1995 was $18 \%$ [25], which has reduced to $11 \%$ in 2012 [26].

\section{PATHOPHYSIOLOGY OF PTDM}

The pathophysiology of PTDM is multifactorial. Throughout this discussion, we will consider risk factors for the development of disease, preand post-transplantation, in addition to factors associated with the allograft itself (Fig. 2).

\section{Pre-Transplantation Risk Factors}

PTDM is more likely to occur in patients with pre-existing risk factors for the development of type $2 \mathrm{DM}$ including increased age, family history of type 2 diabetes, high-risk ethnicities and obesity. The incidence of PTDM is considerably higher in patients of African-American, Asian and Hispanic ethnicity, recipients aged $>$ 40 years and those with a BMI $>30 \mathrm{~kg} / \mathrm{m}^{2}$ $[27,28]$.

\section{Genetic Risk Factors}

Studies have demonstrated an association between single-nucleotide polymorphisms (SNPs) in candidate genes implicated in the pathogenesis of non-transplant-associated diabetes mellitus and the development of PTDM. One study demonstrated that polymorphisms in the HNF-4A gene and the insulin receptor substrate 1 gene were significantly associated with the development of PTDM in renal allograft recipients of Hispanic ethnicity [29]. Additional SNPs that increase the risk of PTDM have been found in genes including TCF7L2, KCNJ11-Kir6.2, IL and NFATc4 [29-32]. Patients carrying multiple predisposing SNPs have a greater risk of PTDM. 


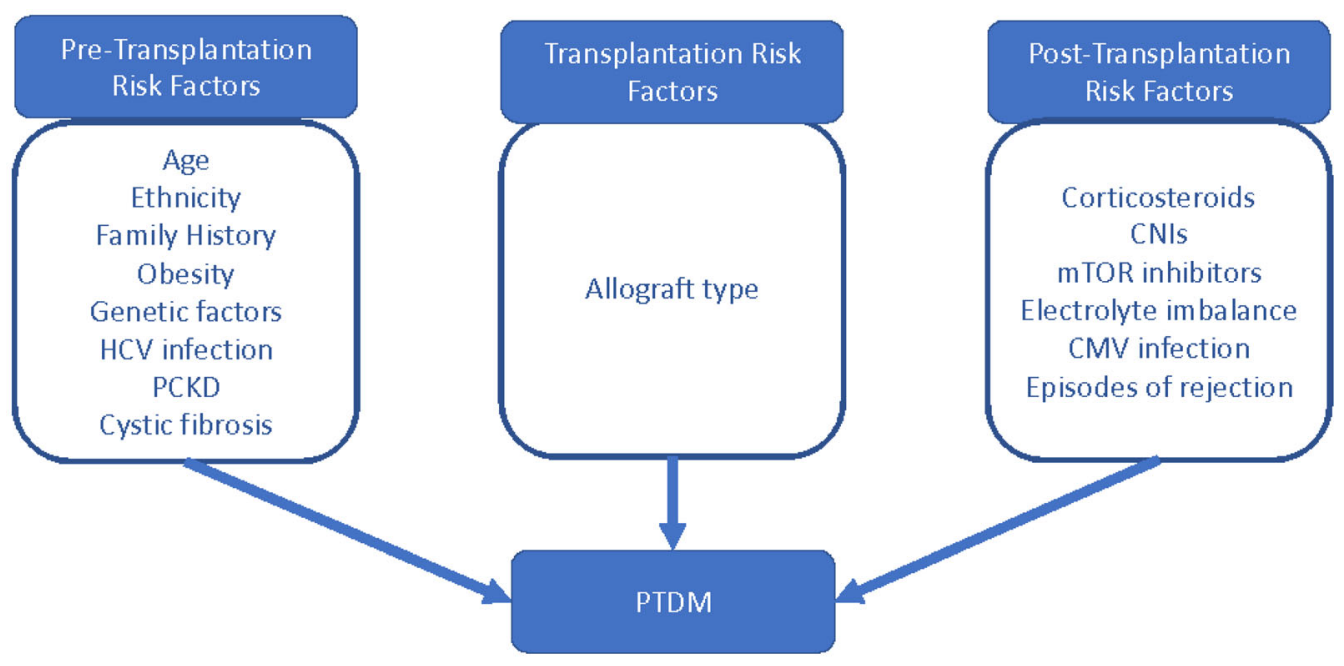

Fig. 2 Risk factors for PTDM. $H C V$ hepatitis $\mathrm{C}$ virus, $P C K D$ polycystic kidney disease, $C N I$ calcineurin inhibitor, $m$ TOR mammalian target of rapamycin, $C M V$ cytomegalovirus

\section{Pre-Transplantation Medical Comorbidities}

Pre-transplantation medical comorbidities have been shown to influence the risk of PTDM development. In particular, hepatitis $\mathrm{C}$ virus (HCV) infection, cystic fibrosis (CF) and polycystic kidney disease (PCKD) are thought to increase the risk of diabetes after transplantation [33].

$\mathrm{HCV}$ infection is recognised to have a predisposition to the development of diabetes in nontransplant patients. Furthermore, evidence suggests that $\mathrm{HCV}$ infection increases the risk of PTDM [34]. A meta-analysis of liver-transplant recipients demonstrated that the prevalence of PTDM in HCV-positive patients was higher than the prevalence in HCV-negative patients [34]. $\mathrm{HCV}$ infection has also been shown to be a risk factor for the development of PTDM in patients after renal transplantation [35]. Studies investigating the pathogenesis of PTDM have shown that HCV-positive organ recipients have significantly reduced insulin sensitivity compared with matched HCV-negative recipients. Conversely, $\mathrm{HCV}$ infection has not been shown to influence insulin secretion or hepatic insulin uptake [36].

\section{Transplantation-Associated Risk Factors}

Allograft-associated factors, including graft type, have been shown to affect the incidence of
PTDM. It is well established that deceased donor allografts express higher levels of proinflammatory cytokines compared with living donor allografts, and it has been hypothesised that the resulting proinflammatory state predisposes to the development of PTDM. This is supported by markedly increased rates of PTDM in recipients of deceased donor grafts compared with living donor grafts, with some studies demonstrating a relative risk of nearly four [37].

\section{Post-Transplantation Risk Factors}

Post-transplantation risk factors include the immunosuppressive regimen used for induction and maintenance, cytomegalovirus (CMV) infection and episodes of rejection.

\section{Steroids}

Corticosteroids have a dual role in transplant immunosuppression. High-dose steroids are used in the induction of immunosuppression perioperatively and lower and tapering doses are used for long-term maintenance therapy.

Corticosteroids are well known to cause hyperglycaemia and predispose to the development of diabetes. The mechanisms underlying corticosteroid-induced diabetes include 
impaired insulin sensitivity, increased hepatic gluconeogenesis and appetite stimulation with resulting weight gain. As the hyperglycaemic effect of glucocorticoids is dose-dependent, induction protocols have a greater diabetogenic potential than long-term maintenance doses [33]. Trials of early steroid discontinuation postoperatively have shown limited success in reducing rates of PTDM with marginal non-significant rates of efficacy [27, 38]. High-dose steroid pulses are also given during the maintenance phase to treat rejection episodes. These can precipitate the onset of diabetes.

\section{Calcineurin Inhibitors (CNIs)}

CNIs currently form the mainstay of most immunosuppressive regimens for the prevention of organ rejection. The two main CNIs include tacrolimus and cyclosporine. Extensive evidence supports the efficacy of CNIs in the prevention of immunological rejection but have highlighted adverse effects including predisposition to the development of PTDM. The diabetogenic potential of CNIs varies between medications and evidence suggests that tacrolimus is more diabetogenic than cyclosporine. A large meta-analysis of renal transplantation patients, comparing data from 30 randomised control trials, demonstrated that tacrolimus was more efficacious at preventing graft loss and acute rejection than cyclosporine. However, the incidence of insulin-treated diabetes was greater in the patients receiving tacrolimus, at 1 year following transplantation (RR 1.86) and increased with higher doses of tacrolimus $(p=0.003)$ [39].

CNIs are thought to promote the development of PTDM through multiple mechanisms. CNIs have been shown to impair insulin secretion in clinical studies of patients receiving tacrolimus [40]. Both animal and human studies, analysing pancreatic histology sections, have demonstrated increased islet cell apoptosis and decreased beta cell mass in groups receiving CNIs [41, 42].

At a molecular level, calcineurin is thought to play an important role in the survival of beta cells in the pancreas through the activation of the transcription factors nuclear factor of activated T-cells (NFAT) and cAMP response element binding protein (CREB) (Fig. 3).

CREB is believed to mediate the proliferative effects of glucagon-like peptide (GLP-1) and transgenic mice that express a dominant negative CREB protein develop diabetes with apoptosis of beta cells secondary to reduced insulin receptor substrate (IRS2) expression [43]. Studies in animal models suggest that NFAT also stimulates IRS2 transcription and CNIs are thought to downregulate IRS2 expression through the inhibition of both NFAT and CREB [44]. Current data suggest that IRS2 stimulates insulin secretion via the P13K/Akt pathway. Supporting evidence includes studies where calcineurin inhibition has been shown to reduce Akt phosphorylation in both murine and human islets [44].

Mixed evidence exists regarding the effect of CNIs on peripheral insulin sensitivity. In vitro analyses suggest that therapeutic levels of cyclosporine and tacrolimus inhibit glucose uptake into adipose cells through the stimulation of endocytosis of GLUT 4 transporters from the cell surface [45]. Conversely, clinical studies have failed to demonstrate a significant in vivo effect of CNIs on insulin sensitivity. Rickels et al. investigated insulin sensitivity in patients after islet cell transplantation using an insulinmodified IV glucose tolerance test. The results revealed no significant difference in insulin sensitivity among the three groups tested (islet cell transplant patients immunosuppressed with CNIs, type 1 diabetic patients and healthy controls) [46]. Further clinical studies are required to clarify the in vivo relevance of CNIs on insulin sensitivity.

Electrolyte abnormalities associated with tacrolimus use are thought to increase the risk of hyperglycaemia and PTDM. Hypomagnesaemia is a common adverse effect of tacrolimus use and has been identified as an independent risk factor for insulin resistance and hyperglycaemia [47]. Van Laecke et al. have demonstrated that hypomagnesaemia within the first month post-transplant was associated with the development of PTDM [48]. 


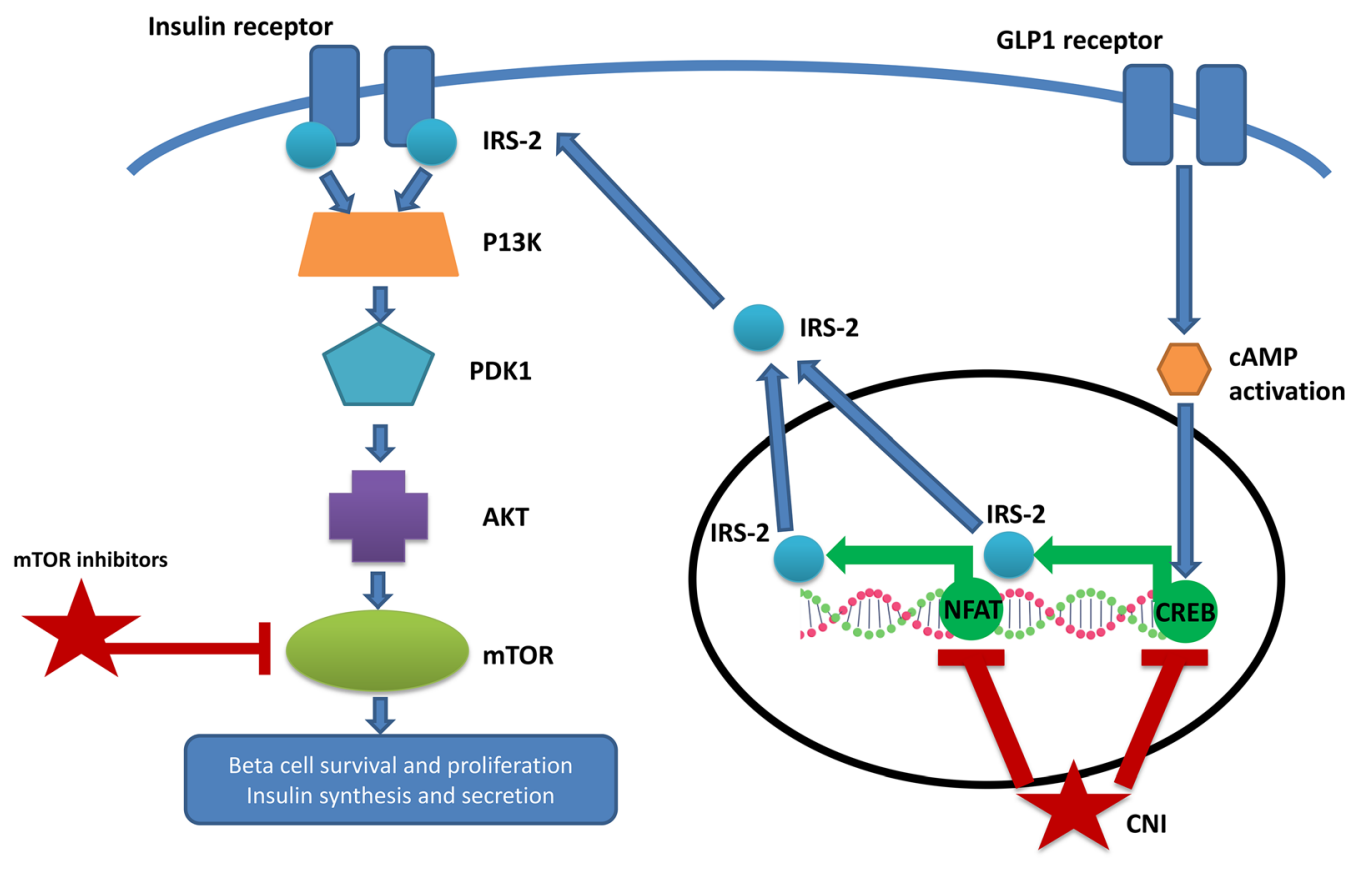

Fig. $3 \mathrm{mTORi}$ and CNI affect the insulin signalling cascade. IRS2 insulin receptor substrate, PDKI phosphoinositide-dependent protein kinase, PI3K phosphatidylinositol 3 kinase, $C A M P$ cyclic adenosine monophosphate, NFAT transcription factors nuclear factor of activated

\section{Mammalian Target of Rapamycin Inhibitors (mTORi)}

mTOR inhibitors, such as sirolimus, are used in several immunosuppressive regimens both with and without CNIs. Extensive clinical evidence suggests that sirolimus is an independent risk factor for the development of PTDM. A large retrospective 10-year study found sirolimus therapy to be as important a risk factor for the development of PTDM as obesity or older age and demonstrated an interactive effect with concomitant CNI therapy [49]. The diabetogenic effect of sirolimus may be lower than that of CNIs and case reports suggest that conversion to sirolimus from CNIs improved glycaemic control in patients with PTDM [50].

mTOR inhibitors are thought to influence the development of PTDM via multiple mechanisms, including impaired insulin secretion and reduced insulin signal transduction (Fig. 2). Like CNIs, mTOR inhibitors have been shown to induce apoptosis of rat and human pancreatic islet cells in vitro [51]. Furthermore, it has been

T-cells, $C R E B$ cAMP response element binding protein, CNI calcineurin inhibitor, $m$ TOR mammalian target of rapamycin, GLP1 glucagon-like peptide-1

demonstrated that sirolimus impairs pancreatic ductal proliferation and reduces ductal cell numbers in culture. This evidence translated to impaired glucose-stimulated insulin secretion in mice treated with sirolimus [52].

The effect of mTOR inhibitors on insulin signalling is thought to be of a greater importance that the effect on insulin secretion. Like CNIs, mTOR inhibitors act on the insulin receptor-IRSPI3K-Akt pathway. Evidence has shown that stimulation of the mTOR-containing complex (mTORC1) is required for the activation of Akt and the resulting simulation of protein synthesis. Through binding to mTOR, sirolimus stimulates the phosphorylation and inhibition of IRS-1 leading to the inhibition of P13K/Akt signalling [33].

Support for this model comes from animal studies where it has been shown that treatment with sirolimus results in a dose-dependent increase in hyperglycaemia and hyperinsulinaemia, in response to oral glucose challenge, suggesting impaired insulin sensitivity [41]. Furthermore, sirolimus has been shown to 
suppress Akt phosphorylation secondary to insulin secretion [53] and interfere with the phosphorylation of mTORC2, reducing insulinmediated inhibition of hepatic gluconeogenesis [54]. Some human studies have not reported an effect of sirolimus on insulin sensitivity including a study in healthy, slim individuals [55]. These negative results have led to the question of whether underlying susceptibility to type 2 diabetes, which is common after transplantation, is required for the pathogenesis of disease in the context of sirolimus therapy.

\section{Infection}

$\mathrm{CMV}$ is an opportunistic infection associated with transplantation and immunosuppression. Evidence that CMV infection plays a role in the pathogenesis of PTDM is mixed but larger metaanalyses and observation suggest that $\mathrm{CMV}$ infection is an independent risk factor for the development of PTDM. One meta-analysis included results from 1389 renal transplant recipients and found that CMV-positive patients had a relative risk of 1.94 of developing PTDM compared with CMV-negative patients [56]. Possible mechanisms underlying the diabetogenic effects of CMV infection include CMV-mediated destruction of pancreatic beta cell or the production of pro-inflammatory cytokines, but further work is required to investigate these mechanisms further [33].

\section{Rejection}

Rejection after transplantation has been shown to predispose to the development of PTDM. A large study calculated a hazard ratio of 3.7 of developing PTDM in patients with acute cellular rejection [57]. However, these results are hard to interpret as it is difficult to disentangle the effects of rejection versus the effects of anti-rejection therapy, which involves high-dose steroid pulses and increased CNIs.

In conclusion, many factors influence an individual's risk for the development of PTDM. Identification and optimisation of risk factors before transplantation and early post-transplant are vital to prevent the onset of PTDM and improve glycaemic control once established. An awareness and identification of high-risk individuals can lead to early recognition, prompt diagnosis and effective therapy, which contributes to improved quality of life, extended graft life and reduced mortality.

\section{COMPLICATIONS OF PTDM}

\section{Graft and Patient Survival}

Several studies have shown that PTDM is associated with greater mortality, reduced survival [58-62], poor graft outcomes [61-63] and deathcensored graft failure [62]. The increased rate of mortality has been attributed to cardiovascular events $[5,60,63]$, increased risk of opportunistic infections and sepsis-related mortality $[5,63]$. In one study, rates of death and graft loss were shown to be lower in patients with PTDM than without [38].

A later observational study examining the relationship among PTDM patients treated with medications, PTDM patients managed without medications and those without diabetes, on overall survival and survival with a functioning graft, showed no significant difference in allograft survival, death-censored allograft failure among these groups; but drug-treated PTDM was independently associated with shorter patient survival with a functioning allograft, higher all-cause mortality and death [64].

There is a recognizable trend for later studies to show better graft survival and mortality rates because of the following factors: change in the diagnostic criteria for PTDM, more efficacious immunosuppression, greater awareness of this condition leading to earlier detection and treatment, a greater variety of glucose-lowering agents available and pro-active management of PTDM.

Many of the studies are limited in their ability to give conclusive answers because of small sample sizes or short follow-up times or inherent designs.

\section{Microvascular Complications}

De novo nephropathy has been described in transplant kidneys following development of PTDM [65, 66]. A recently published 
longitudinal study has shown that patients with PTDM develop long-term microvascular complications of neuropathy, nephropathy of a milder form compared with type 1 and type 2 DM [67].

\section{MANAGEMENT}

\section{Prevention}

Strict attention to diabetes reduction strategies will reduce individual patient morbidity, costs in the management of diabetes and improve long-term quality of life (QoL), patient and graft survival.

Despite the importance of PTDM as a major cause of post-transplant morbidity, mortality, increased cost and patient anxiety, there is a paucity of randomised controlled trials exploring interventions that can attenuate the development of diabetes in these metabolically highrisk post-transplant recipients.

The cardiometabolic milieu of transplantation patients is different from that of the general population because of immunosuppressant side effects, weight gain and fatigue being more common post-transplantation.

\section{Diet, Physical Activity, Lifestyle Intervention}

Transplantation poses many metabolic challenges to the recipient: changes in energy expenditure, hormonal and fluid/electrolyte changes and the effects of immunosuppressive therapy. Low glycaemic diet in non-transplant patients with type $2 \mathrm{DM}$ and hypertension is associated with lower micro- and macrovascular complications [68, 69]. In post-transplant patients, there is no published randomized controlled trial (RCT) that has explored dietary changes to the incidence of PTDM.

In the Diabetes Prevention Programme (DPP), lifestyle intervention has been shown to delay the onset of diabetes by $58 \%$ and this effect can persist for at least 10 years [70]. In kidney transplant recipients, lifestyle intervention can reduce the incidence and ameliorate existing glucose intolerance or PTDM [71].

Weight gain in the range of $6-10 \mathrm{~kg}$ is common in the first 6 months after kidney transplantation [72]. Early dietetic intervention, recommendation for an exercise programme and weight loss advice would be beneficial. Patients with a BMI $>30$ should be encouraged to lose weight before surgery.

Post-transplant weight gain, particularly visceral fat gain, increases the risk of developing PTDM, dyslipidaemia and CVD [72]. Hence, lifestyle modification including dietetic input and weight loss advice should be part of routine care for patients with PTDM.

\section{Treatment of Hypomagnesaemia}

Hypomagnesaemia associated with CNI treatment is a known risk factor for PTDM. Randomized controlled trials have so far not conclusively proven that oral magnesium supplementation in the post-transplant period improves insulin resistance or secretion [73, 74]. Further research through large prospective studies is required to ascertain whether correction of hypomagnesaemia would prevent PTDM.

\section{Treatment of CMV and HCV Infection}

Gursoy et al. have shown that HCV-infected patients who did not receive interferon (IFN) had a higher frequency rate of PTDM [75]. CMV prophylaxis with valganciclovir has not shown any effect on incidence of PTDM [76].

\section{Gut Microbiome}

It has been shown experimentally in SpragueDawley rats that probiotic use can reverse hyperglycaemia by reversing the altered biodiversity associated with tacrolimus and sirolimus use [77]. It has yet to be proven experimentally in humans and is an area for further research.

\section{Pharmacotherapy}

Metformin has been shown to improve tacrolimus/sirolimus-induced hyperglycaemia in Sprague-Dawley rats and reduces exocrine apoptosis [53]. It has also been shown to improve glucose intolerance caused by sirolimus in genetically heterogeneous HET3 mice [78].

Peroxisome proliferator-activated gamma $(\mathrm{PPAR} \gamma)$ receptor activation with rosiglitazone 
has been shown to attenuate glucose intolerance induced by sirolimus in rats [79].

Hecking et al. showed that use of isophane insulin in the immediate-post-operative phase was associated with $73 \%$ lower odds of developing PTDM (odds ratio, 0.27) in comparison to a control group, which consisted of patients who were treated with short-acting insulin \pm oral agents. The treatment group showed better $\beta$-cell function throughout the 1-year follow-up and were insulin independent [80]. It was hypothesized that insulin therapy afforded beta-cell protection by reducing glucotoxicity and associated apoptosis.

A placebo-controlled RCT showed non-significant decrease in the 2-h plasma glucose with vildagliptin and pioglitazone [81].

\section{Individualized Immunosuppressive Therapy}

Modern immunosuppression should be individualized taking into consideration specific factors that could be modulated for optimum outcomes. Diabetes prevention is one such important factor. It has been proposed that cyclosporine should be considered for immunosuppression in patients with a greater diabetes risk due to a reduced risk in causing PTDM compared with tacrolimus [82]. However, over time glucose intolerance begins to manifest even with cyclosporine therapy [83].

Conversion from a CNI to sirolimus in patients could significantly improve the metabolic parameters of patients with PTDM, without increasing the risk of acute rejection [50].

A Cochrane review of 83 studies that involved 16,156 participants did not show any difference among CNI withdrawal, low-dose $\mathrm{CNI}$ and standard regimes on the incidence of diabetes [84].

A meta-analysis, examining 11,337 patients from 56 randomized controlled trials, demonstrates that all evaluated protocols (CNI avoidance, minimization and delayed introduction) are effective in improving renal function without increasing the incidence of rejection. CNIsparing protocols were not associated with different rates of PTDM compared with CNI-based regimens when 38 studies $(n=7305)$ were analysed. However, eight studies $(n=2943)$ that specifically utilized current diagnostic guidelines for PTDM demonstrated reduced rates of PTDM with reduced exposure CNI [85]. A recent post hoc analysis from two large multicentre trials have shown no difference in the incidence or severity of PTDM with early conversion from a cyclosporine-based regimen to everolimus or in the progression of pre-existing diabetes [86].

A Cochrane review looking at 5 studies involving 521 patients, comparing belatacept with other CNIs in kidney transplant patients has shown a lower incidence of PTDM with belatacept. Belatacept-treated patients had a better graft function, better blood pressure and lipid profile [87].

\section{Glycaemic Management}

In the peritransplant phase in the hospital, hyperglycaemia is attributed to induction agents, steroids and underlying recipient diabetogenic morbidity, and glycemia is usually well controlled with insulin therapy. The diagnosis of PTDM may be delayed until after discharge, when the patient is stable and immunosuppression is reduced to maintenance doses, with stable allograft function without infections. This review will cover outpatient management, with the currently available pharmacotherapy (Table 3). We propose a flow diagram for the glycaemic management of patients after transplant surgery, based on our experience (Fig. 4).

\section{Metformin}

There is no particular algorithm agreed by consensus for the management of PTDM.

Metformin, a first-line therapy for treatment of type 2 diabetes in non-transplant patients has been used for treatment of PTDM [9]. Metformin exerts pleiotropic actions beyond its glucose-lowering agent effect leading to several clinical benefits including anti-neoplastic, cardiovascular protection, lipid-lowering benefits, anti-inflammatory and attenuation of non-alcoholic fatty liver disease, and anti-endothelial function [88].

Weight gain is common among organ recipients, with average weight gains of $8-14 \mathrm{~kg}$ 


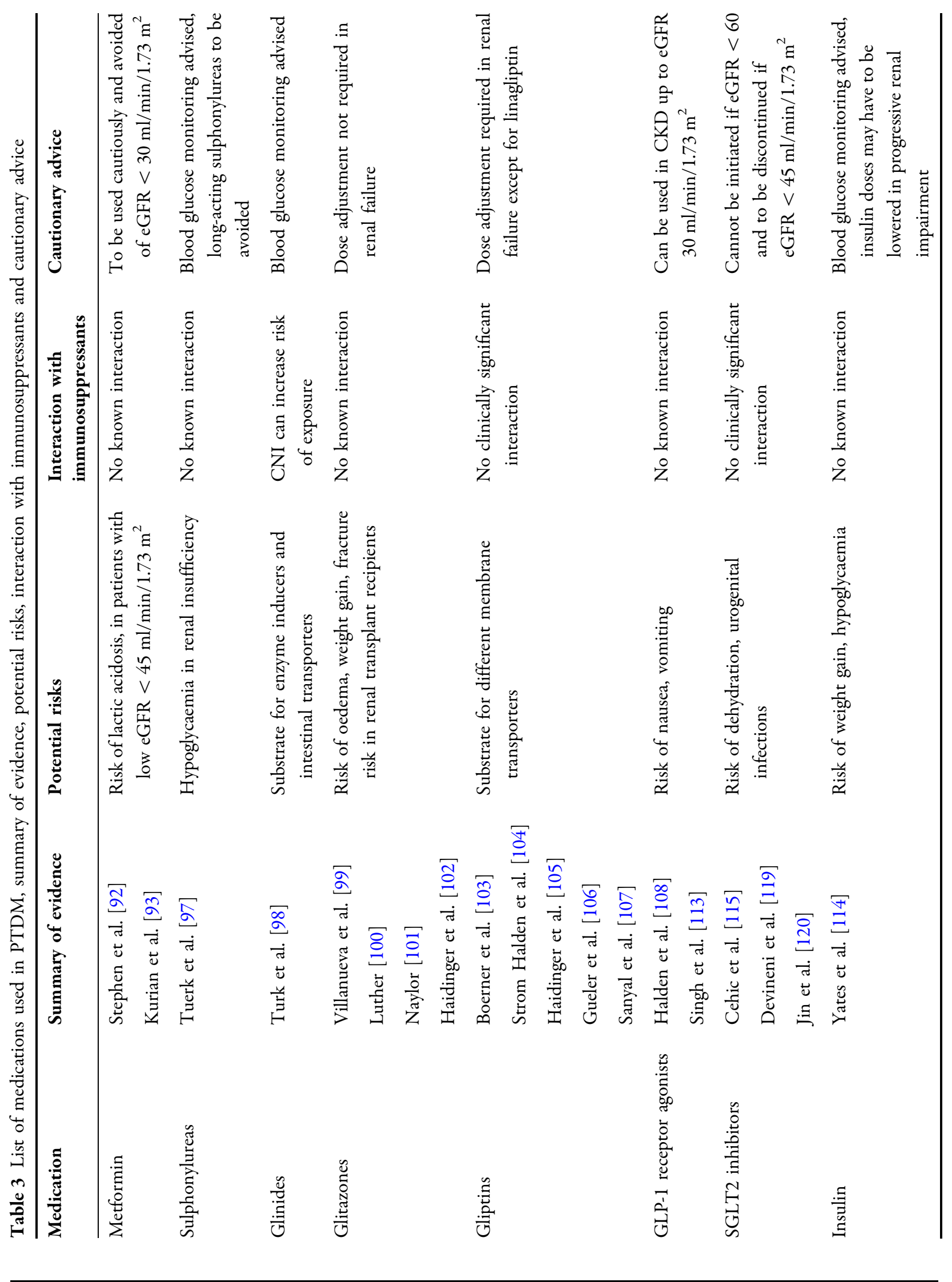




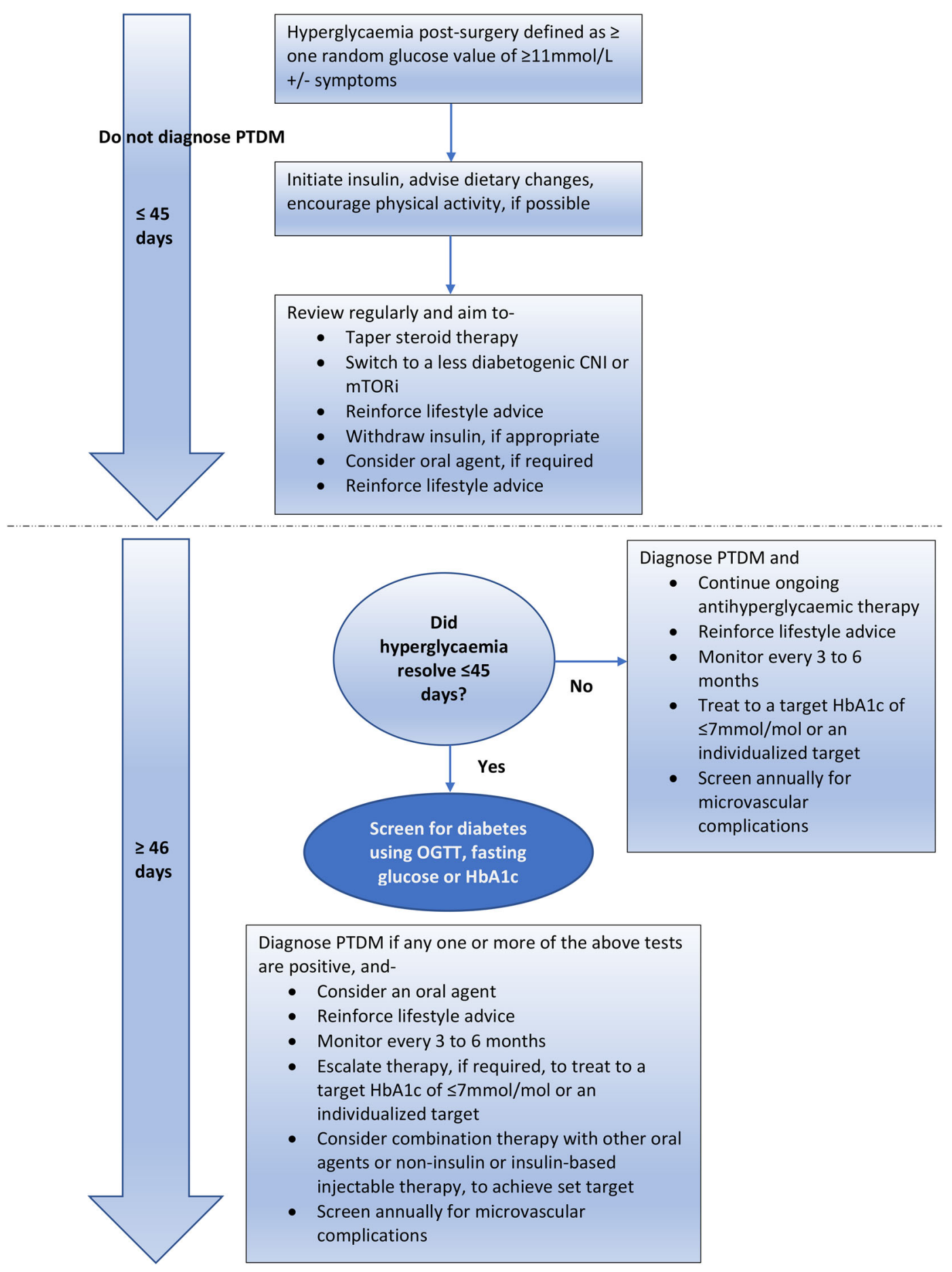

Fig. 4 Flow diagram depicting proposed glycaemic management after transplant surgery

in the first-year post-transplantation [89]. A recent Cochrane review and meta-analysis, which included randomized controlled trials of over 12-week duration [90], found metformin to be weight neutral compared with placebo or diet in the general population. Compared with sulphonylureas, metformin had a weighted mean difference in weight of $\sim 2.9 \mathrm{~kg}(95 \% \mathrm{CI}$ -4.4 to -1.1$)$. 
In the post-transplant phase, with delayed graft function, infections and the use of contrast agents, the use of metformin could be associated with lactic acidosis. Hence, caution is advised especially at times of critical illness as it can be associated with 30\% mortality [91]. However, a large registry analysis in the USA of 47,000 patients showed that there was no difference in patient or allograft survival between metformin users and non-users [92]. A small retrospective study of metformin safety and effectiveness in renal transplant patients has not shown a significant of side effects or change in HbA1c after 16.4 months of metformin use [93].

Metformin is not metabolized and is excreted unchanged in the urine. Though it is a substrate for multiple transporters in the gut, liver and kidney, i.e. plasma membrane monoamine transporter (PMAT), organic cation transporter (OCT) 1-3 and multidrug and toxin extrusion transporter (MATE)- 1 and $-2 \mathrm{~K}$, it does not cause any drug interactions with immunosuppressive agents [94].

\section{Sulphonylureas and Glinides}

Sulphonylureas and glinides provide their therapeutic action by stimulating pancreatic insulin secretion. Sulphonylureas can be associated with increased cardiovascular risk and loss of durability after prolonged use [95, 96]. All sulphonylureas except for gliquidone are excreted by the kidney; there is the potential risk of prolonged hypoglycaemia in the context of renal insufficiency [97]. Long-acting agents such as glibenclamide should be avoided in view of this risk. The Glinides, repaglinide and nateglinide, on the other hand, are shorter acting and are eliminated extensively by the liver. They are a substrate for the enzyme inducers CYP3A4, -2C8 CYP2C9, -3A4 and the intestinal transporter TP1B1 (OATP1B1); thereby, concomitant CNI use can increase the risk of exposure to these agents. Despite these theoretical risks, clinically significant risk has not been noted with repaglinide [98].

\section{Glitazones}

The glitazones work by increasing insulin sensitivity and glucose uptake in muscle and adipose tissue along with lowering circulating and hepatic free fatty acids (FFA). Dose adjustment is not required in renal impairment. Both rosiglitazone and pioglitazone have been shown to be effective in the management of PTDM in small studies [99, 100]. The significant side effect profile of oedema, weight gain and increased fracture risk, which is inherently high in patients after transplantation [101], makes them less favourable agents for therapy in PTDM.

\section{Dipeptidyl Peptidase-4 (DPP-4) Inhibitors}

DDP-4 inhibitors act by increasing the half-life of the native incretin hormones GLP-1 and gastric inhibitory polypeptide (GIP) by inhibiting the degradation by inhibition of the enzyme DPP-4 in a glucose-dependant manner. All the DDP-4 inhibitors expect linagliptin are excreted by the kidney and require dose adjustment in renal impairment. They have been found to be effective and safe in the treatment of PTDM [102]. Sitagliptin has been shown to be effective and safe in short-term retrospective studies [103, 104].

Vildagliptin has been shown to significantly and safely lower HbA1c and 2-h plasma glucose in a phase II, placebo-controlled RCT [105]. In a non-randomized, controlled retrospective trial in patients after cardiac transplantation, vildagliptin has been shown to be effective in reducing HbA1c and mean blood glucose levels, without affecting the weight, lipid profile or immunosuppressive drug levels [106].

Linagliptin was evaluated in a retrospective study of 21 patients on tacrolimus and was found to effectively reduce fasting, post-prandial glucose and HbA1c, without causing significant altering tacrolimus levels or side effects [107].

Sitagliptin is a substrate for p-glycoprotein and organic anion transporter-3 (OAT3), OATP4C1, whereas all the other gliptins are a substrate for p-glycoprotein. A CNI such as cyclosporine is a potent inhibitor of p-glycoprotein. However, concomitant use does not affect the pharmacokinetics of the gliptins in a clinically meaningful way [94]. Studies to date have shown that gliptins probably have no significant effect on CNI or mTORi metabolism 
with the possible exception of sitagliptin and cyclosporine (increase in cyclosporine trough levels) as well as tacrolimus and vildagliptin (decrease in tacrolimus trough levels) [94].

\section{GLP-1 Receptor Agonists}

GLP-1 receptor agonists function by delaying gastric emptying, promoting insulin secretion in a glucose-dependant manner and suppressing glucagon secretion and appetite. They have also been shown to be protective on beta cell function in the long term. In an experimental study GLP-1 infusion reduced glucagon concentrations and increased first- and secondphase insulin secretion in patients with PTDM [108].

Liraglutide [109], semaglutide [110] and more recently albiglutide [111] have been shown to reduce the risk of major adverse cardiac events (MACE). Besides the glucose-lowering effect, they have non-glycaemic benefits such as improvement in insulin resistance, weight loss, reduction in blood pressure, improved lipid profile and direct effect on the heart and the vascular endothelium. Dose adjustment of liraglutide and semaglutide is not required for mild, moderate to severe renal impairment.

There is a concern that delayed gastric emptying caused by GLP-1 agonists can affect absorption of orally administered immunosuppressive agents, potentially leading to insufficient peak levels within a narrow therapeutic window. A case series demonstrated that tacrolimus trough levels are not affected by co-administration of liraglutide [112]. A real-world retrospective study has shown that both liraglutide and dulaglutide are safe, efficacious and well tolerated in patients with SOT without any interference with immunosuppressive therapy [113]. With dulaglutide, there was sustained reduction in weight, BMI, insulin requirement and HbA1c compared with liraglutide. GLP-1 agonists are potential agents for treatment of PTDM given their multifaceted effects and minimal renal clearance, but further research is required to establish their safety, efficacy and long-term effects on micro- and macrovascular complications.

\section{Insulin}

Insulin therapy is required if other treatments are not tolerated or contraindicated or because of renal impairment precluding the use of oral agents. In PTDM, glucose levels have been shown to be lowest between 2:00 and 8:00 and highest between 14:00 and 20:00 [114]. Hence, insulin with a pharmacokinetic profile resulting in a peak after mid-day such as a biphasic insulin administered in the morning would be more useful. The treatment regimen would have to be tailored on an individual basis.

\section{SGLT2 Inhibitors}

There is presently no robust research evidence to support the use of SGLT2 inhibitors in PTDM. In patients with heart transplants, empagliflozin was shown to produce clinical reduction in body weight and blood pressure and a nonsignificant reduction in HBA1c. After 147 cumulative months of empagliflozin use, no adverse events such as diabetic ketoacidosis (DKA) or genitourinary infections were reported [115]. They are promising agents because of specific benefits, i.e. weight loss, low risk of hypoglycaemia, renoprotection, cardioprotection, and reduction in incidence and admissions with heart failure [116-118]. They cannot be initiated in patients with an eGFR $<60 \mathrm{ml} /$ $\mathrm{min} / 1.73 \mathrm{~m}^{2}$ and should be discontinued when eGFR $<45 \mathrm{ml} / \mathrm{min} / 1.73 \mathrm{~m}^{2}$. Notably, in the EMPA-REG study, patients with an eGFR of $30 \mathrm{ml} / \mathrm{min} / 1.73 \mathrm{~m}^{2}$ were part of the study [116]. No clinically meaningful interaction was noted between cyclosporine and canagliflozin in healthy participants [119].

In small experimental studies, empagliflozin has been shown to alleviate tacrolimus-induced renal and pancreatic cell injury, thereby stabilising and improving the resulting renal dysfunction and hyperglycaemia [120].

\section{Bariatric Surgery}

Randomized controlled trials in patients with type 2 DM undergoing bariatric surgery have shown sustained diabetes remission in 30-63\% of the patients [121]. Although there are no studies formally assessing metabolic surgery in PTDM, this can be offered as a mean for diabetes 
amelioration/remission in obese patients (BMI $\geq 35$ ) affected by obesity-related complications and impaired QoL [122].

\section{Prevention of CV Disease}

Atherosclerotic cardiovascular disease is quite prevalent in patients after kidney transplantation. Aspirin reduces atherosclerotic cardiovascular events in patients with known CVD [123]. Low-dose aspirin is therefore recommended for secondary prevention [124].

\section{Management of Dyslipidaemia}

Following transplantation, in addition to the elevated triglycerides and decreased HDL cholesterol, the non-HDL cholesterol and total cholesterol are frequently elevated. This is contributed by the use of immunosuppressive therapy, relative insulin deficiency associated with PTDM and other risk factors in this population such as obesity and advancing age. Cyclosporine increases LDL cholesterol via both increased production and decreased clearance.

Corticosteroids increase TC, VLDL and triglyceride levels in a dose-dependent manner by exacerbating insulin resistance. The adverse effects of cyclosporine and corticosteroids on lipid levels appear to be additive [125]. Tacrolimus and azathioprine appear to have less induction of dyslipidaemia than cyclosporine [126]. Sirolimus increases both cholesterol and triglycerides, in part due to decreased LDL clearance [127].

Kidney Disease Improving Global Outcomes (KDIGO) guidelines recommend checking the lipid profile at 2-3 months after transplantation or change in treatment and at least annually thereafter [128]. All renal transplant patients are considered at high risk of ischaemic heart disease (IHD). The guidelines recommend treating LDL cholesterol to a target of $<100 \mathrm{mg} / \mathrm{dl}$ $(2.59 \mathrm{mmol} / \mathrm{l})$ [129]. The medication of choice is a statin, the starting dose of which has to be calculated bearing in mind potential drug-drug interaction in patients treated with cyclosporine or tacrolimus. A long-term follow-up study in renal transplant patients with fluvastatin has shown that major adverse cardiac events and mortality were reduced [130]. Pravastatin and simvastatin have demonstrated improved outcomes in cardiac transplant patients [131, 132]. A Cochrane database review has shown a strong trend towards reduced CVD events and mortality with statins in renal transplant patients [133].

Severe hypertriglyceridaemia, which can be associated with sirolimus and everolimus therapy, should be treated first to avert the potential risk of pancreatitis [134]. Fibrates can be used with immunosuppressants but have to be used cautiously with statins because of the increased risk of statin-induced myopathy with the combination. Fish oils lower triglycerides but their effect on graft function in renal transplant patients is unknown [135].

Drug interactions must be borne in mind as cyclosporine and tacrolimus are metabolized by CYP3A4 and can potentially increase systemic exposure to a statin increasing the risk of myopathy. Fluvastatin, pravastatin, pitavastatin and rosuvastatin have less potential for interaction [136].

Ezetimibe has been shown to be a well-tolerated and efficacious alternative in those who are intolerant to statin or in whom this is contraindicated [137].

Sometimes severe dyslipidaemia may warrant change in the immunosuppressive therapy or steroid dose reduction or withdrawal [138, 139].

It has been shown that circulating proprotein convertase subtilisin/kexin type 9 (PCSK9) is significantly associated with development of PTDM in renal transplant patients [140], but there is no intervention study that has tested whether its inhibition would reduce the incidence of PTDM.

\section{Management of Hypertension}

Hypertension is common in patients before and after kidney transplantation. Post-transplant factors that contribute to it are use of immunosuppressive agents, use of steroids, weight gain, renal artery stenosis, graft rejection or chronic allograft nephropathy. KDIGO 
recommends measuring blood pressure at every clinic visit. It also suggests maintaining blood pressure at $<130 \mathrm{mmHg} \quad$ systolic and $<80 \mathrm{mmHg}$ diastolic if $\geq 18$ years of age [141]. Hypertension is an independent risk factor for CVD after kidney transplantation [142].

The choice of the initial antihypertensive agent depends on associated co-morbid conditions, the presence or absence of proteinuria, and post-transplant complications that may contraindicate the use of a particular antihypertensive agent. Angiotensin-converting enzyme inhibitors or angiotensin II type 1 receptor blockers have no particular role in patient or graft survival following renal transplantation [143]. A Cochrane review has shown that calcium channel blockers improve graft function and reduce the risk of graft loss compared with ACEi which were associated with worsening eGFR, low haemoglobin and increased risk of hyperkalaemia [144]. Calcium channel blockers may be the first-line agents for hypertensive kidney transplant patients. Antihypertensives such as beta-blockers and thiazide diuretics may be associated with hyperglycaemia. Beta-blockers that have a neutral effect or favourable effect on glucose homeostasis include carvedilol, labetalol, pindolol and nebivolol.

\section{CONCLUSION}

PTDM affects graft survival and mortality and is associated with long-term complications. The need to manage transplant-induced diabetes detracts from the quality of life achieved by transplantation. Consensus criteria for the diagnosis of post-transplant diabetes are now firmly established and their implementation allows for timely diagnosis and treatment. This should improve long-term outcomes. Awareness that transplantation could be associated with the onset of diabetes prior to transplantation can lead to early implementation of a prevention strategy with dietary and lifestyle changes as part of the overall post-transplant management. Although tailored individual immunosuppressive therapy would help, the priority of care after transplantation should be focussed on using the most appropriate combination of agents to prevent graft failure, even it if comes with an attendant risk of PTDM. Management of PTDM can be complex given the other problems related to transplantation such as profiles of immunosuppressive agents including steroid-associated metabolic changes, variable kidney function, drug interactions, changes in activity, exercise and body habitus. Treatment strategies should be individualized to the patient. We advise a collabortive multidisciplinary approach to the care of such patients, involving members of the specialist diabetes and transplant teams. Further research in this field will definitely add to the current repertoire of knowledge and management strategies in what is an important post-transplant morbidity.

\section{ACKNOWLEDGEMENTS}

Funding. No funding or sponsorship was received for the write-up or publication of this article.

Authorship. All named authors meet the International Committee of Medical Journal Editors (ICMJE) criteria for authorship for this article, take responsibility for the integrity of the work as a whole, and have given their approval for this version to be published.

Disclosures. The authors (S Haris Ahmed, Kathryn Biddle and Titus Augustine) have nothing to disclose. Shazli Azmi is an editorial board member of the journal but otherwise has nothing else to disclose.

Compliance with Ethics Guidelines. This article is based on previously conducted studies and does not contain any studies with human participants or animals performed by any of the authors.

Data Availability. Data sharing is not applicable to this article as no datasets were generated or analyzed during the current study. 
Open Access. This article is licensed under a Creative Commons Attribution-NonCommercial 4.0 International License, which permits any non-commercial use, sharing, adaptation, distribution and reproduction in any medium or format, as long as you give appropriate credit to the original author(s) and the source, provide a link to the Creative Commons licence, and indicate if changes were made. The images or other third party material in this article are included in the article's Creative Commons licence, unless indicated otherwise in a credit line to the material. If material is not included in the article's Creative Commons licence and your intended use is not permitted by statutory regulation or exceeds the permitted use, you will need to obtain permission directly from the copyright holder. To view a copy of this licence, visit http://creativecommons.org/licenses/by$\mathrm{nc} / 4.0 /$.

\section{REFERENCES}

1. Black CK, Termanini KM, Aguirre O, Hawksworth JS, Sosin M. Solid organ transplantation in the 21(st) century. Ann Transl Med. 2018;6(20):409.

2. Valderhaug TG, Hjelmesaeth J, Jenssen T, Roislien J, Leivestad T, Hartmann A. Early posttransplantation hyperglycemia in kidney transplant recipients is associated with overall long-term graft losses. Transplantation. 2012;94(7):714-20.

3. Matas AJ, Gillingham KJ, Humar A, Ibrahim HN, Payne WD, Gruessner RWG, et al. Posttransplant diabetes mellitus and acute rejection: impact on kidney transplant outcome. Transplantation. 2008;85(3):338-43.

4. Pietrzak-Nowacka M, Safranow K, Dziewanowski K, Debska-Slizien A, Glyda M, Golembiewska E, et al. Impact of posttransplant diabetes mellitus on graft function in autosomal dominant polycystic kidney disease patients after kidney transplantation. Ann Acad Med Stetin. 2008;54(1):41-8.

5. Siraj ES, Abacan C, Chinnappa P, Wojtowicz J, Braun W. Risk factors and outcomes associated with posttransplant diabetes mellitus in kidney transplant recipients. Transplant Proc. 2010;42(5): $1685-9$.

6. Sharif A, Hecking M, de Vries APJ, Porrini E, Hornum M, Rasoul-Rockenschaub S, et al. Proceedings from an international consensus meeting on posttransplantation diabetes mellitus: recommendations and future directions. Vol. 14, American journal of transplantation: official journal of the American Society of Transplantation and the American Society of Transplant Surgeons. United States; 2014. pp. 1992-2000.

7. Davidson J, Wilkinson A, Dantal J, Dotta F, Haller $\mathrm{H}$, Hernandez $\mathrm{D}$, et al. New-onset diabetes after transplantation: 2003 International consensus guidelines. Proceedings of an international expert panel meeting. Barcelona, Spain, 19 February 2003. Transplantation. 2003;75(10 Suppl):SS3-24.

8. Wilkinson A, Davidson J, Dotta F, Home PD, Keown P, Kiberd B, et al. Guidelines for the treatment and management of new-onset diabetes after transplantation. Clin Transplant. 2005;19(3):291-8.

9. Association AD. Diagnosis and classification of diabetes mellitus. Diabetes Care [Internet]. 2011;34 Suppl 1(Suppl 1):S62-9. https://www.ncbi.nlm.nih. gov/pubmed/21193628.

10. Valderhaug TG, Jenssen T, Hartmann A, Midtvedt $\mathrm{K}$, Holdaas $\mathrm{H}$, Reisaeter AV, et al. Fasting plasma glucose and glycosylated hemoglobin in the screening for diabetes mellitus after renal transplantation. Transplantation. 2009;88(3):429-34.

11. Sharif A, Moore RH, Baboolal K. The use of oral glucose tolerance tests to risk stratify for new-onset diabetes after transplantation: an underdiagnosed phenomenon. Transplantation. 2006;82(12):1667-72.

12. Hecking M, Kainz A, Werzowa J, Haidinger M, Doller D, Tura A, et al. Glucose metabolism after renal transplantation. Diabetes Care. 2013;36(9): 2763-71.

13. Hecking M, Werzowa J, Haidinger $\mathrm{M}$, Horl WH, Pascual J, Budde K, et al. Novel views on new-onset diabetes after transplantation: development, prevention and treatment. Nephrol Dial Transplant. 2013;28(3):550-66.

14. Caillard S, Eprinchard L, Perrin P, Braun L, Heibel F, Moreau $\mathrm{F}$, et al. Incidence and risk factors of glucose metabolism disorders in kidney transplant recipients: role of systematic screening by oral glucose tolerance test. Transplantation. 2011;91(7):757-64.

15. Valderhaug TG, Hjelmesaeth J, Hartmann A, Roislien J, Bergrem HA, Leivestad T, et al. The association of early post-transplant glucose levels with long-term mortality. Diabetologia. 2011;54(6): 1341-9.

16. Jenssen T, Hartmann A. Post-transplant diabetes mellitus in patients with solid organ transplants. Nat Rev Endocrinol. 2019;15(3):172-88. 
17. Vincenti F, Friman S, Scheuermann E, Rostaing L, Jenssen T, Campistol JM, et al. Results of an international, randomized trial comparing glucose metabolism disorders and outcome with cyclosporine versus tacrolimus. Am J Transplant. 2007;7(6):1506-14.

18. Woodward RS, Schnitzler MA, Baty J, Lowell JA, Lopez-Rocafort L, Haider S, et al. Incidence and cost of new onset diabetes mellitus among U.S. waitlisted and transplanted renal allograft recipients. Am J Transplant. 2003;3(5):590-8.

19. Jenssen T, Hartmann A. Emerging treatments for post-transplantation diabetes mellitus. Nat Rev Nephrol. 2015;11(8):465-77.

20. Cho MS, Choi H-I, Kim I-O, Jung S-H, Yun T-J, Lee $\mathrm{J}-\mathrm{W}$, et al. The clinical course and outcomes of posttransplantation diabetes mellitus after heart transplantation. J Korean Med Sci. 2012;27(12):1460-7.

21. Kim HJ, Jung S-H, Kim J-J, Yun T-J, Kim JB, Choo SJ, et al. New-onset diabetes mellitus after heart transplantation: incidence, risk factors and impact on clinical outcome. Circ J. 2017;81(6):806-14.

22. Nieuwenhuis MG, Kirkels JH. Predictability and other aspects of post-transplant diabetes mellitus in heart transplant recipients. J Heart Lung Transplant. 2001;20(7):703-8.

23. Linder KE, Baker WL, Rochon C, May ST, Sheiner PA, Martin ST. Evaluation of posttransplantation diabetes mellitus after liver transplantation: assessment of insulin administration as a risk factor. Ann Pharmacother. 2016;50(5):369-75.

24. Moon JI, Barbeito R, Faradji RN, Gaynor JJ, Tzakis AG. Negative impact of new-onset diabetes mellitus on patient and graft survival after liver transplantation: long-term follow up. Transplantation. 2006;82(12):1625-8.

25. Hjelmesaeth J, Hartmann A, Kofstad J, Stenstrom J, Leivestad T, Egeland T, et al. Glucose intolerance after renal transplantation depends upon prednisolone dose and recipient age. Transplantation. 1997;64(7):979-83.

26. von During ME, Jenssen T, Bollerslev J, Asberg A, Godang K, Eide IA, et al. Visceral fat is better related to impaired glucose metabolism than body mass index after kidney transplantation. Transpl Int. 2015;28(10):1162-71.

27. Walczak DA, Calvert D, Jarzembowski TM, Testa G, Sankary HN, Thielke J, et al. Increased risk of posttransplant diabetes mellitus despite early steroid discontinuation in Hispanic kidney transplant recipients. Clin Transplant. 2005;19(4):527-31.
28. Peracha J, Nath J, Ready A, Tahir S, Parekh K, Hodson J, et al. Risk of post-transplantation diabetes mellitus is greater in South Asian versus Caucasian kidney allograft recipients. Transpl Int. 2016;29(6):727-39.

29. Chen Y, Sampaio MS, Yang JW, Min D, Hutchinson IV. Genetic polymorphisms of the transcription factor NFATc4 and development of new-onset diabetes after transplantation in Hispanic kidney transplant recipients. Transplantation. 2012;93(3): 325-30.

30. Ghisdal L, Baron C, Le Meur Y, Lionet A, Halimi $\mathrm{J}-\mathrm{M}$, Rerolle J-P, et al. TCF7L2 polymorphism associates with new-onset diabetes after transplantation. J Am Soc Nephrol. 2009;20(11):2459-67.

31. Tavira B, Coto E, Torres A, Diaz-Corte C, DiazMolina B, Ortega F, et al. Association between a common KCNJ11 polymorphism (rs5219) and newonset posttransplant diabetes in patients treated with Tacrolimus. Mol Genet Metab. 2012;105(3): 525-7.

32. Kim YG, Ihm C-G, Lee TW, Lee SH, Jeong KH, Moon JY, et al. Association of genetic polymorphisms of interleukins with new-onset diabetes after transplantation in renal transplantation. Transplantation. 2012;93(9):900-7.

33. Shivaswamy V, Boerner B, Larsen J. Post-transplant diabetes mellitus: causes, treatment, and impact on outcomes. Endocr Rev. 2016;37(1):37-61.

34. Naing C, Mak JW, Ahmed SI, Maung M. Relationship between hepatitis $C$ virus infection and type 2 diabetes mellitus: meta-analysis. World J Gastroenterol. 2012;18(14):1642-51.

35. Fabrizi F, Martin P, Dixit V, Bunnapradist S, Kanwal F, Dulai G. Post-transplant diabetes mellitus and HCV seropositive status after renal transplantation: Meta-analysis of clinical studies. Am J Transplant. 2005.

36. Baid-Agrawal S, Frei U, Reinke P, Schindler R, Kopp MA, Martus $P$, et al. Impaired insulin sensitivity as an underlying mechanism linking hepatitis $\mathrm{C}$ and posttransplant diabetes mellitus in kidney recipients. Am J Transplant. 2009;9(12):2777-84.

37. Gourishankar S, Jhangri GS, Tonelli M, Wales LH, Cockfield SM. Development of diabetes mellitus following kidney transplantation: a Canadian experience. Am J Transplant. 2004;4(11):1876-82.

38. Pirsch JD, Henning AK, First MR, Fitzsimmons W, Gaber AO, Reisfield R, et al. New-onset diabetes after transplantation: results from a double-blind early corticosteroid withdrawal trial. Am J Transplant. 2015;15(7):1982-90. 
39. Webster AC, Woodroffe RC, Taylor RS, Chapman JR, Craig JC. Tacrolimus versus ciclosporin as primary immunosuppression for kidney transplant recipients: meta-analysis and meta-regression of randomised trial data. BMJ. 2005;331(7520):810.

40. Fuji S, Kim S-W, Mori S, Furuta K, Tanosaki R, Heike $Y$, et al. Decreased insulin secretion in patients receiving tacrolimus as GVHD prophylaxis after allogeneic hematopoietic SCT. Vol. 45, Bone marrow transplantation. England; 2010. pp. 405-6.

41. Shivaswamy V, Bennett RG, Clure CC, Ottemann B, Davis JS, Larsen JL, et al. Tacrolimus and sirolimus have distinct effects on insulin signaling in male and female rats. Transl Res. 2014;163(3):221-31.

42. Drachenberg CB, Klassen DK, Weir MR, Wiland A, Fink JC, Bartlett ST, et al. Islet cell damage associated with tacrolimus and cyclosporine: morphological features in pancreas allograft biopsies and clinical correlation. Transplantation. 1999;68(3): 396-402.

43. Jhala US, Canettieri G, Screaton RA, Kulkarni RN, Krajewski S, Reed J, et al. cAMP promotes pancreatic $\beta$-cell survival via CREB-mediated induction of IRS2. Genes Dev. 2003;17:1575-80.

44. Soleimanpour SA, Crutchlow MF, Ferrari AM, Raum JC, Groff DN, Rankin MM, et al. Calcineurin signaling regulates human islet $\beta$-cell survival. J Biol Chem. 2010;285(51):40050-9.

45. Asberg A, Midtvedt K, Voytovich MH, Line P-D, Narverud J, Reisaeter AV, et al. Calcineurin inhibitor effects on glucose metabolism and endothelial function following renal transplantation. Clin Transplant. 2009;23(4):511-8.

46. Rickels MR, Naji A, Teff KL. Insulin sensitivity, glucose effectiveness, and free fatty acid dynamics after human islet transplantation for type 1 diabetes. J Clin Endocrinol Metab. 2006;91(6): 2138-44.

47. Lima Mde L, Cruz T, Rodrigues LE, Bomfim O, Melo J, Correia R, et al. Serum and intracellular magnesium deficiency in patients with metabolic syndrome-Evidences for its relation to insulin resistance. Diabetes Res Clin Pract. 2009;83:257-62.

48. Van Laecke S, Van Biesen W, Verbeke F, De Bacquer D, Peeters P, Vanholder R. Posttransplantation hypomagnesemia and its relation with immunosuppression as predictors of new-onset diabetes after transplantation. Am J Transplant. 2009;9: 2140-9.

49. Gyurus E, Kaposztas Z, Kahan BD. Sirolimus therapy predisposes to new-onset diabetes mellitus after renal transplantation: a long-term analysis of various treatment regimens. Transplant Proc. 2011;43(5):1583-92.

50. Veroux M, Tallarita T, Corona D, Sinagra N, Giaquinta A, Zerbo D, et al. Conversion to sirolimus therapy in kidney transplant recipients with new onset diabetes mellitus after transplantation. Clin Dev Immunol. 2013;2013:496974.

51. Bell E, Cao X, Moibi JA, Greene SR, Young R, Trucco $\mathrm{M}$, et al. Rapamycin has a deleterious effect on MIN6 cells and rat and human islets. Diabetes. 2003;52(11):2731-9.

52. Bussiere CT, Lakey JRT, Shapiro AMJ, Korbutt GS. The impact of the mTOR inhibitor sirolimus on the proliferation and function of pancreatic islets and ductal cells. Diabetologia. 2006;49(10):2341-9.

53. Shivaswamy V, Bennett RG, Clure CC, Larsen JL, Hamel FG. Metformin improves immunosuppressant induced hyperglycemia and exocrine apoptosis in rats. Transplantation. 2013;95(2):280-4.

54. Lamming DW, Ye L, Katajisto P, Goncalves MD, Saitoh M, Stevens DM, et al. Rapamycin-induced insulin resistance is mediated by mTORC2 loss and uncoupled from longevity. Science. 2012;335(6076):1638-43.

55. Krebs M, Brunmair B, Brehm A, Artwohl M, Szendroedi J, Nowotny P, et al. The Mammalian target of rapamycin pathway regulates nutrient-sensitive glucose uptake in man. Diabetes. 2007;56(6): 1600-7.

56. Einollahi B, Motalebi M, Salesi M, Ebrahimi M, Taghipour M. The impact of cytomegalovirus infection on new-onset diabetes mellitus after kidney transplantation: a review on current findings. J Nephropathol. 2014;3(4):139-48.

57. Schweer T, Gwinner W, Scheffner I, Schwarz A, Haller H, Blume C. High impact of rejection therapy on the incidence of post-transplant diabetes mellitus after kidney transplantation. Clin Transplant. 2014;28(4):512-9.

58. Revanur VK, Jardine AG, Kingsmore DB, Jaques BC, Hamilton DH, Jindal RM. Influence of diabetes mellitus on patient and graft survival in recipients of kidney transplantation. Clin Transplant. 2001;15(2):89-94.

59. Cosio FG, Pesavento TE, Kim S, Osei K, Henry M, Ferguson RM. Patient survival after renal transplantation: IV. Impact of post-transplant diabetes. Kidney Int. 2002;62(4):1440-6.

60. Wauters RP, Cosio FG, Suarez Fernandez ML, Kudva Y, Shah P, Torres VE. Cardiovascular consequences 
of new-onset hyperglycemia after kidney transplantation. Transplantation. 2012;94(4):377-82.

61. Cole EH, Johnston O, Rose CL, Gill JS. Impact of acute rejection and new-onset diabetes on longterm transplant graft and patient survival. Clin J Am Soc Nephrol. 2008;3(3):814-21.

62. Kasiske BL, Snyder JJ, Gilbertson D, Matas AJ. Diabetes mellitus after kidney transplantation in the United States. Am J Transplant. 2003;3(2):178-85.

63. Gaynor JJ, Ciancio G, Guerra G, Sageshima J, Hanson L, Roth D, et al. Single-centre study of 628 adult, primary kidney transplant recipients showing no unfavourable effect of new-onset diabetes after transplant. Diabetologia. 2015;58(2):334-45.

64. Dienemann T, Fujii N, Li Y, Govani S, Kosaraju N, Bloom RD, et al. Long-term patient survival and kidney allograft survival in post-transplant diabetes mellitus: a single-center retrospective study. Transpl Int. 2016;29(9):1017-28.

65. Koselj M, Rott T, Koselj MK, Hvala A, Arnol M, Kandus A. De novo diabetic nephropathy on renal allografts. Transplant Proc. 2003;35(8):2919-21.

66. Miles AM, Sumrani N, Horowitz R, Homel P, Maursky V, Markell MS, et al. Diabetes mellitus after renal transplantation: as deleterious as non-transplant-associated diabetes? Transplantation. 1998;65(3):380-4.

67. Londero TM, Giaretta LS, Farenzena LP, Manfro RC, Canani LH, Lavinsky D, et al. Microvascular complications of posttransplant diabetes mellitus in kidney transplant recipients: a longitudinal study. J Clin Endocrinol Metab. 2019;104(2):557-67.

68. Nolte Fong JV, Moore LW. Nutrition trends in kidney transplant recipients: the importance of dietary monitoring and need for evidence-based recommendations. Front Med. 2018;5:302.

69. van Wijngaarden RPT, Overbeek JA, Heintjes EM, Schubert A, Diels J, Straatman H, et al. Relation between different measures of glycemic exposure and microvascular and macrovascular complications in patients with type 2 diabetes mellitus: an observational cohort study. Diabetes Ther [Internet]. 2017;8(5):1097-109. https://doi.org/10.1007/ s13300-017-0301-4.

70. Group DPPR, Knowler WC, Fowler SE, Hamman RF, Christophi CA, Hoffman HJ, et al. 10-year follow-up of diabetes incidence and weight loss in the Diabetes Prevention Program Outcomes Study. Lancet (London, England) [Internet]. 2009/10/29. 2009;374(9702):1677-86. https://www.ncbi.nlm. nih.gov/pubmed/19878986.
71. Sharif A, Moore R, Baboolal K. Influence of lifestyle modification in renal transplant recipients with postprandial hyperglycemia. Transplantation. 2008;85(3):353-8.

72. Weight Aksoy N, Transplant Gain After Kidney. Exp Clin Transplant. 2016;14(Suppl 3):138-40.

73. Van Laecke S, Nagler EV, Taes Y, Van Biesen W, Peeters P, Vanholder R. The effect of magnesium supplements on early post-transplantation glucose metabolism: a randomized controlled trial. Transpl Int. 2014;27(9):895-902.

74. Van Laecke S, Caluwe R, Huybrechts I, Nagler EV, Vanholder R, Peeters P, et al. Effect of magnesium supplements on insulin secretion after kidney transplantation: a randomized controlled trial. Ann Transplant. 2017;22:524-31.

75. Gursoy M, Koksal R, Karavelioglu D, Colak T, Gur G, Ozdemir N, et al. Pretransplantation alpha-interferon therapy and the effect of hepatitis $\mathrm{C}$ virus infection on kidney allograft recipients. Transplant Proc. 2000;32(3):580-2.

76. Humar A, Lebranchu Y, Vincenti F, Blumberg EA, Punch JD, Limaye AP, et al. The efficacy and safety of 200 days valganciclovir cytomegalovirus prophylaxis in high-risk kidney transplant recipients. Am J Transplant. 2010;10(5):1228-37.

77. Bhat M, Pasini E, Copeland J, Angeli M, Husain S, Kumar D, et al. Impact of immunosuppression on the metagenomic composition of the intestinal microbiome: a systems biology approach to posttransplant diabetes. Sci Rep. 2017;7(1):10277.

78. Weiss R, Fernandez E, Liu Y, Strong R, Salmon AB. Metformin reduces glucose intolerance caused by rapamycin treatment in genetically heterogeneous female mice. Aging (Albany NY). 2018;10(3): 386-401.

79. Festuccia WT, Blanchard P-G, Belchior T, Chimin P, Paschoal VA, Magdalon J, et al. PPARgamma activation attenuates glucose intolerance induced by mTOR inhibition with rapamycin in rats. Am J Physiol Endocrinol Metab. 2014;306(9):E1046-54.

80. Hecking M, Haidinger M, Doller D, Werzowa J, Tura A, Zhang J, et al. Early basal insulin therapy decreases new-onset diabetes after renal transplantation. J Am Soc Nephrol. 2012;23(4):739-49.

81. Werzowa J, Hecking M, Haidinger M, Lechner F, Doller D, Pacini G, et al. Vildagliptin and pioglitazone in patients with impaired glucose tolerance after kidney transplantation: a randomized, placebo-controlled clinical trial. Transplantation. 2013;95(3):456-62. 
82. Snowsill TM, Moore J, Mujica Mota RE, Peters JL, Jones-Hughes TL, Huxley NJ, et al. Immunosuppressive agents in adult kidney transplantation in the National Health Service: a model-based economic evaluation. Nephrol Dial Transplant. 2017;32(7):1251-9.

83. Batista F, Auyanet I, Torregrosa J-V, Oppenheimer F. Long-term follow-up after conversion from tacrolimus to cyclosporin in renal transplant patients with new-onset diabetes mellitus after transplantation. Transplant Proc. 2012;44(9):2582-4.

84. Karpe KM, Talaulikar GS, Walters GD. Calcineurin inhibitor withdrawal or tapering for kidney transplant recipients. Cochrane database Syst Rev. 2017; 7:CD006750.

85. Sharif A, Shabir S, Chand S, Cockwell P, Ball S, Borrows R. Meta-analysis of calcineurin-inhibitorsparing regimens in kidney transplantation. J Am Soc Nephrol. 2011;22(11):2107-18.

86. Sommerer C, Witzke O, Lehner F, Arns W, Reinke P, Eisenberger $U$, et al. Onset and progression of diabetes in kidney transplant patients receiving everolimus or cyclosporine therapy: an analysis of two randomized, multicenter trials. BMC Nephrol. 2018;19(1):237.

87. Masson P, Henderson L, Chapman JR, Craig JC, Webster AC. Belatacept for kidney transplant recipients. Cochrane database Syst Rev. 2014;(11): CD010699.

88. Sharif A. Should metformin be our antiglycemic agent of choice post-transplantation? Am J Transplant. 2011;11(7):1376-81.

89. Potluri K, Hou S. Obesity in kidney transplant recipients and candidates. Am J Kidney Dis. 2010;56(1):143-56.

90. Saenz A, Fernandez-Esteban I, Mataix A, Ausejo M, Roque M, Moher D. Metformin monotherapy for type 2 diabetes mellitus. Cochrane Database Syst Rev. 2005;(3):CD002966.

91. Peters N, Jay N, Barraud D, Cravoisy A, Nace L, Bollaert P-E, et al. Metformin-associated lactic acidosis in an intensive care unit. Crit Care. 2008;12(6):R149.

92. Stephen J, Anderson-Haag TL, Gustafson S, Snyder JJ, Kasiske BL, Israni AK. Metformin use in kidney transplant recipients in the United States: an observational study. Am J Nephrol. 2014;40(6): 546-53.

93. Kurian B, Joshi R, Helmuth A. Effectiveness and long-term safety of thiazolidinediones and metformin in renal transplant recipients. Endocr Pract. 2008;14(8):979-84.

94. Vanhove T, Remijsen Q, Kuypers D, Gillard P. Drugdrug interactions between immunosuppressants and antidiabetic drugs in the treatment of posttransplant diabetes mellitus. Transplant Rev (Orlando). 2017;31(2):69-77.

95. Azoulay L, Suissa S. Sulfonylureas and the risks of cardiovascular events and death: a methodological meta-regression analysis of the observational studies. Diabetes Care. 2017;40(5):706-14.

96. Maedler K, Carr RD, Bosco D, Zuellig RA, Berney T, Donath MY. Sulfonylurea induced beta-cell apoptosis in cultured human islets. J Clin Endocrinol Metab. 2005;90(1):501-6.

97. Tuerk TR, Bandur S, Nuernberger J, Kribben A, Mann K, Philipp T, et al. Gliquidone therapy of new-onset diabetes mellitus after kidney transplantation. Clin Nephrol. 2008;70(1):26-32.

98. Turk T, Pietruck F, Dolff S, Kribben A, Janssen OE, Mann K, et al. Repaglinide in the management of new-onset diabetes mellitus after renal transplantation. Am J Transplant. 2006;6(4):842-6.

99. Villanueva G, Baldwin D. Rosiglitazone therapy of posttransplant diabetes mellitus. Transplantation. 2005;80(10):1402-5.

100. Luther P, Baldwin DJ. Pioglitazone in the management of diabetes mellitus after transplantation. Am J Transplant. 2004;4(12):2135-8.

101. Naylor KL, Jamal SA, Zou G, McArthur E, Lam NN, Leslie WD, et al. Fracture incidence in adult kidney transplant recipients. Transplantation. 2016;100(1): 167-75.

102. Haidinger M, Antlanger M, Kopecky C, Kovarik JJ, Saemann MD, Werzowa J. Post-transplantation diabetes mellitus: evaluation of treatment strategies. Clin Transplant. 2015;29(5):415-24.

103. Boerner BP, Miles CD, Shivaswamy V. Efficacy and safety of sitagliptin for the treatment of new-onset diabetes after renal transplantation. Int J Endocrinol. 2014;2014:617638.

104. Strom Halden TA, Asberg A, Vik K, Hartmann A, Jenssen T. Short-term efficacy and safety of sitagliptin treatment in long-term stable renal recipients with new-onset diabetes after transplantation. Nephrol Dial Transplant. 2014;29(4):926-33.

105. Haidinger M, Werzowa J, Hecking M, Antlanger M, Stemer G, Pleiner J, et al. Efficacy and safety of vildagliptin in new-onset diabetes after kidney transplantation-a randomized, double-blind, placebo- 
controlled trial. Am J Transplant. 2014;14(1): 115-23.

106. Gueler I, Mueller S, Helmschrott M, Oeing CU, Erbel C, Frankenstein L, et al. Effects of vildagliptin (Galvus(R)) therapy in patients with type 2 diabetes mellitus after heart transplantation. Drug Des Devel Ther. 2013; 7:297-303.

107. Sanyal D, Gupta S, Das P. A retrospective study evaluating efficacy and safety of linagliptin in treatment of NODAT (in renal transplant recipients) in a real world setting. Indian J Endocrinol Metab. 2013;17(Suppl 1):S203-5.

108. Halden TAS, Egeland EJ, Asberg A, Hartmann A, Midtvedt K, Khiabani HZ, et al. GLP-1 restores altered insulin and glucagon secretion in posttransplantation diabetes. Diabetes Care. 2016;39(4): 617-24.

109. Marso SP, Daniels GH, Brown-Frandsen K, Kristensen P, Mann JFE, Nauck MA, et al. Liraglutide and cardiovascular outcomes in type 2 diabetes. N Engl J Med. 2016;375(4):311-22.

110. Marso SP, Bain SC, Consoli A, Eliaschewitz FG, Jodar E, Leiter LA, et al. Semaglutide and cardiovascular outcomes in patients with type 2 diabetes. N Engl J Med. 2016;375(19):1834-44.

111. Hernandez AF, Green JB, Janmohamed S, D'Agostino RBS, Granger CB, Jones NP, et al. Albiglutide and cardiovascular outcomes in patients with type 2 diabetes and cardiovascular disease (Harmony Outcomes): a double-blind, randomised placebo-controlled trial. Lancet (London, England). 2018;392(10157):1519-29.

112. Pinelli NR, Patel A, Salinitri FD. Coadministration of liraglutide with tacrolimus in kidney transplant recipients: a case series. Vol. 36, Diabetes care. United States; 2013. p. e171-2.

113. Singh P, Taufeeq M, Pesavento TE, Washburn K, Walsh D, Meng S. Comparison of two glucagonlike-peptide-1 analogs (GLP-1) dulaglutide vs liraglutide for the management of diabetes in solid organ transplant (SOT). Diabetes Obes Metab. 2020 (Epub ahead of print).

114. Yates CJ, Fourlanos S, Colman PG, Cohney SJ. Screening for new-onset diabetes after kidney transplantation: limitations of fasting glucose and advantages of afternoon glucose and glycated hemoglobin. Transplantation. 2013;96(8):726-31.

115. Cehic MG, Muir CA, Greenfield JR, Hayward C, Jabbour A, Keogh A, et al. Efficacy and safety of empagliflozin in the management of diabetes mellitus in heart transplant recipients. Transplant direct. 2019;5(5):e450.
116. Zinman B, Wanner C, Lachin JM, Fitchett D, Bluhmki E, Hantel S, et al. Empagliflozin, cardiovascular outcomes, and mortality in type 2 diabetes. N Engl J Med. 2015;373(22):2117-28.

117. Neal B, Perkovic V, Mahaffey KW, de Zeeuw D, Fulcher G, Erondu N, et al. Canagliflozin and cardiovascular and renal events in type 2 diabetes. N Engl J Med. 2017;377(7):644-57.

118. Wiviott SD, Raz I, Bonaca MP, Mosenzon O, Kato ET, Cahn A, et al. Dapagliflozin and cardiovascular outcomes in type 2 diabetes. $\mathrm{N}$ Engl J Med. 2019;380(4):347-57.

119. Devineni D, Vaccaro N, Murphy J, Curtin C, Mamidi RNVS, Weiner S, et al. Effects of rifampin, cyclosporine $\mathrm{A}$, and probenecid on the pharmacokinetic profile of canagliflozin, a sodium glucose co-transporter 2 inhibitor, in healthy participants. Int J Clin Pharmacol Ther. 2015;53(2):115-28.

120. Jin J, Jin L, Luo K, Lim SW, Chung BH, Yang CW. Effect of empagliflozin on tacrolimus-induced pancreas islet dysfunction and renal injury. Am J Transplant. 2017;17(10):2601-16.

121. Rubino F, Nathan DM, Eckel RH, Schauer PR, Alberti KGMM, Zimmet PZ, et al. Metabolic surgery in the treatment algorithm for type 2 diabetes: a joint statement by international diabetes organizations. Diabetes Care. 2016;39(6):861-77.

122. Chen JH, Lee CH, Chang CM, Yin WY. Successful management of new-onset diabetes mellitus and obesity with the use of laparoscopic sleeve gastrectomy after kidney transplantation-a case report. Transplant Proc. 2016;48(3):938-9.

123. Patrono C, Bachmann F, Baigent C, Bode C, De Caterina R, Charbonnier B, et al. Expert consensus document on the use of antiplatelet agents. The task force on the use of antiplatelet agents in patients with atherosclerotic cardiovascular disease of the European society of cardiology. Eur Heart J. 2004;25(2):166-81.

124. Smith SCJ, Allen J, Blair SN, Bonow RO, Brass LM, Fonarow GC, et al. AHA/ACC guidelines for secondary prevention for patients with coronary and other atherosclerotic vascular disease: 2006 update: endorsed by the National Heart, Lung, and Blood Institute. Circulation. 2006;113(19):2363-72.

125. Hricik DE, Mayes JT, Schulak JA. Independent effects of cyclosporine and prednisone on posttransplant hypercholesterolemia. Am J Kidney Dis. 1991;18(3):353-8.

126. Marcen R, Chahin J, Alarcon A, Bravo J. Conversion from cyclosporine microemulsion to tacrolimus in stable kidney transplant patients with 
hypercholesterolemia is related to an improvement in cardiovascular risk profile: a prospective study. Transplant Proc. 2006;38(8):2427-30.

127. Ma KL, Ruan XZ, Powis SH, Chen Y, Moorhead JF, Varghese Z. Sirolimus modifies cholesterol homeostasis in hepatic cells: a potential molecular mechanism for sirolimus-associated dyslipidemia. Transplantation. 2007;84(8):1029-36.

128. KDIGO clinical practice guideline for the care of kidney transplant recipients. Am J Transplant. 2009;9(Suppl 3):S1-155.

129. Kasiske B, Cosio FG, Beto J, Bolton K, Chavers BM, Grimm RJ, et al. Clinical practice guidelines for managing dyslipidemias in kidney transplant patients: a report from the Managing Dyslipidemias in Chronic Kidney Disease Work Group of the National Kidney Foundation Kidney Disease Outcomes Quality Initiative. Am J Transplant. 2004;4(Suppl 7):13-53.

130. Holdaas H, Fellstrom B, Cole E, Nyberg G, Olsson AG, Pedersen TR, et al. Long-term cardiac outcomes in renal transplant recipients receiving fluvastatin: the ALERT extension study. Am J Transplant. 2005;5(12):2929-36.

131. Kobashigawa JA, Katznelson S, Laks H, Johnson JA, Yeatman L, Wang XM, et al. Effect of pravastatin on outcomes after cardiac transplantation. N Engl J Med. 1995;333(10):621-7.

132. Wenke K, Meiser B, Thiery J, Nagel D, von Scheidt W, Steinbeck G, et al. Simvastatin reduces graft vessel disease and mortality after heart transplantation: a four-year randomized trial. Circulation. 1997;96(5):1398-402.

133. Navaneethan SD, Perkovic V, Johnson DW, Nigwekar SU, Craig JC, Strippoli GFM. HMG CoA reductase inhibitors (statins) for kidney transplant recipients. Cochrane database Syst Rev. 2009;(2): CD005019.

134. Subramaniam S, Zell JA, Kunz PL. Everolimus causing severe hypertriglyceridemia and acute pancreatitis. J Natl Compr Canc Netw. 2013;11(1):5-9.

135. Lim AKH, Manley KJ, Roberts MA, Fraenkel MB. Fish oil for kidney transplant recipients. Cochrane database Syst Rev. 2007;(2):CD005282.
136. Page RL 2nd, Miller GG, Lindenfeld J. Drug therapy in the heart transplant recipient: part IV: drug-drug interactions. Circulation. 2005;111(2):230-9.

137. Shaw SM, Chaggar P, Ritchie J, Shah MKH, Baynes AC, O'Neill N, et al. The efficacy and tolerability of ezetimibe in cardiac transplant recipients taking cyclosporin. Transplantation. 2009;87(5):771-5.

138. Gonwa T, Mendez R, Yang HC, Weinstein S, Jensik $\mathrm{S}$, Steinberg S. Randomized trial of tacrolimus in combination with sirolimus or mycophenolate mofetil in kidney transplantation: results at 6 months. Transplantation. 2003;75(8):1213-20.

139. Gruessner RW, Sutherland DE, Parr E, Humar A, Gruessner AC. A prospective, randomized, open-label study of steroid withdrawal in pancreas transplantation-a preliminary report with 6-month follow-up. Transplant Proc. 2001;33(1-2):1663-4.

140. Eisenga MF, Zelle DM, Sloan JH, Gaillard CAJM, Bakker SJL, Dullaart RPF. High serum PCSK9 is associated with increased risk of new-onset diabetes after transplantation in renal transplant recipients. Diabetes Care. 2017;40(7):894-901.

141. K/DOQI clinical practice guidelines on hypertension and antihypertensive agents in chronic kidney disease. Am J Kidney Dis. 2004;43(5 Suppl 1): S1-290.

142. Opelz G, Dohler B. Improved long-term outcomes after renal transplantation associated with blood pressure control. Am J Transplant. 2005;5(11): 2725-31.

143. Opelz G, Zeier M, Laux G, Morath C, Dohler B. No improvement of patient or graft survival in transplant recipients treated with angiotensin-converting enzyme inhibitors or angiotensin II type 1 receptor blockers: a collaborative transplant study report. J Am Soc Nephrol. 2006;17(11):3257-62.

144. Cross NB, Webster AC, Masson P, O'Connell PJ, Craig JC. Antihypertensive treatment for kidney transplant recipients. Cochrane database Syst Rev. 2009;(3):CD003598. 